\title{
Gestational diabetes and the neonate: challenges and solutions
}

\author{
This article was published in the following Dove Press journal: \\ Research and Reports in Neonatology \\ 18 February 2015 \\ Number of times this article has been viewed
}

\author{
Alice Stewart ${ }^{\prime}$ \\ Atul Malhotra ${ }^{1,2}$ \\ 'Monash Newborn, Monash Health, \\ ${ }^{2}$ Department of Paediatrics, Monash \\ University, Melbourne, VIC, Australia
}

\begin{abstract}
The prevalence of gestational diabetes mellitus (GDM) is rising worldwide, along with overweight and obesity. In utero exposure to hyperglycemia increases perinatal complications including preterm birth, macrosomia, neonatal respiratory distress, hypoglycemia, and polycythemia. More significantly, GDM places the offspring at risk of insulin resistance and type 2 diabetes mellitus, obesity and cardiovascular disease. The relative contributory roles of the intrauterine environment, shared genes, and postnatal environment on long-term outcomes are not yet fully understood. Maternal obesity in particular remains a significant confounding factor. Opportunities for ameliorating both the perinatal effects and long-term and intergenerational effects of GDM exist at the level of prevention of GDM, screening for and treatment of GDM, and postnatal interventions in offspring.

Keywords: gestational diabetes mellitus, GDM, perinatal complications, long-term complications, hyperinsulinism, macrosomia
\end{abstract}

\section{Introduction}

The rising prevalence of gestational diabetes mellitus (GDM), along with perinatal complications secondary to GDM, and a growing understanding of the significant long-term impacts on offspring of women with GDM, is of increasing importance to obstetric and neonatal clinicians at both an individual and population health level. This review article aims to summarize current literature regarding the diagnostic criteria for GDM, both the perinatal and long-term complications of GDM, and interventions to prevent these complications.

\section{GDM: definition, prevalence, and diagnostic criteria}

GDM has been defined as "any degree of glucose intolerance with onset or first recognition during pregnancy". ${ }^{1}$ Consequently, the diagnosis of GDM includes both previously undiagnosed abnormality of glucose tolerance, and glucose intolerance related to the pregnancy alone which disappears postpartum. However, a definitive diagnosis can only be made in the postpartum period. The prevalence of GDM is rising worldwide and has been reported in the range of 3\%-14\% $\%^{2-4}$ globally, and in the range of 3\%-5\% $\%^{5-8}$ in North America, Europe, and Australia.

Variation in reported prevalence is, in part, determined by differences in approaches to GDM screening. In 2010, the International Association of Diabetes and Pregnancy Study Groups (IADPSG) recommended a standardized international approach to screening and diagnosis of $\mathrm{GDM}^{9}$ based on risk of adverse pregnancy outcome. The IADPSG consensus statement ${ }^{9}$ proposes a one-step $75 \mathrm{~g}$ oral glucose tolerance test
Correspondence: Alice Stewart Monash Newborn, Monash Medical Center, 246 Clayton Road, Clayton, Victoria 3168 , Australia

Tel +6I 395945191

Fax +6I 395946115

Email alice.stewart2@monashhealth.org 
(OGTT) for all women without a preexisting diagnosis of diabetes at 24-28 weeks' gestation. A diagnosis of GDM is made where one or more of the following threshold values are exceeded: fasting, $\geq 5.1 \mathrm{mmol} / \mathrm{L}$; 1 -hour, $\geq 10.0 \mathrm{mmol} / \mathrm{L}$; 2-hour, $\geq 8.5 \mathrm{mmol} / \mathrm{L}$. These threshold values are derived from the HAPO study, ${ }^{10}$ and are the average glucose values at which the odds for primary pregnancy outcomes (birth weight $>90$ th percentile, cord C-peptide $>90$ th percentile, and percentage of newborn body fat $>90$ th percentile) were increased 1.75 times over the estimated odds at mean glucose values in the HAPO study population. ${ }^{9,10}$ The adoption of these new diagnostic criteria has been predicted to result in a per-pregnancy incidence of GDM of almost 20\%, and a two- to threefold increase in prevalence. ${ }^{11,12}$

However, to date, the IADPSG recommendations have not been uniformly adopted (Table 1). In the UK, the NICE ${ }^{13}$ guidelines continue to recommend screening only of highrisk women (raised body mass index, previous macrosomic infant, previous GDM, first degree relative with diabetes, family origin with high prevalence of diabetes). In the United States, the "two-step" National Institutes of Health (NIH) nonfasting one-hour 50 g glucose load test (GLT) at 24-28 weeks, followed by a fasting $100 \mathrm{~g}$ OGTT for those who test positive, remains an alternative option to the IADPSG “one-step” OGTT. ${ }^{14}$ The Australasian Diabetes in Pregnancy Society (ADIPS) has adopted the World Health Organization (WHO) recommendations for the diagnostic classification of hyperglycemia first detected at any time during pregnancy; ${ }^{15,16}$ this is currently under consideration by the Royal Australian and New Zealand College of Obstetricians and Gynaecologists. ${ }^{17}$

\section{Perinatal complications of GDM}

In order to meet the metabolic demands of the developing fetus, normal pregnancy is a state of insulin-resistance, ${ }^{18}$ which in turn results in an increase in insulin production by pancreatic $\beta$-cells. ${ }^{18,19}$ In a pregnancy affected by GDM, pancreatic $\beta$-cell dysfunction means that increased insulin secretion cannot be mounted in response to insulin resistance, leading to maternal hyperglycemia. The effect of this on the fetus is described by the Pedersen hypothesis. ${ }^{20}$ Maternal hyperglycemia results in increased transplacental transfer of glucose to the fetus. Fetal hyperglycemia in turn stimulates fetal pancreatic $\beta$-cells to release insulin, and as insulin is an important growth factor, the outcome is fetal macrosomia. Macrosomia is variably defined as a birth weight greater than 4,000, 4,500, or 5,000 g, ${ }^{21}$ and is characterized by increased subcutaneous fat, increased muscle mass, and a head circumference which plots on a lower centile than weight.

The Pedersen hypothesis is supported by the strong correlation between fetal size and umbilical total insulin, free insulin, and C-peptide, ${ }^{22}$ and more recently by the finding of a linear relationship between maternal glucose and umbilical cord C-peptide with birth weight in the HAPO study. ${ }^{10}$ In addition to the effects of maternal hyperglycemia, maternal insulin resistance also gives rise to excessive fetal

Table I Comparison of IADPSG, NIH, NICE, and ADIPS guidelines for GDM screening

\begin{tabular}{|c|c|c|c|c|}
\hline & IADPSG & NIH & NICE & ADIPS/WHO 2006 \\
\hline Target population & $\begin{array}{l}\text { Universal: all } \\
\text { pregnant women }\end{array}$ & Universal: all pregnant women & $\begin{array}{l}\text { Women with risk factors for GDM: } \\
\text { - } \text { BMI }>30 \mathrm{~kg} / \mathrm{m}^{2} \\
\text { - Previous baby } \geq 4.5 \mathrm{~kg} \\
\text { - Previous GDM } \\
\text { - First-degree relative with DM } \\
\text { - Family origin with high prevalence } \\
\text { of diabetes: South Asian, Black } \\
\text { Caribbean, Middle Eastern }\end{array}$ & $\begin{array}{l}\text { Universal: all pregnant } \\
\text { women }\end{array}$ \\
\hline $\begin{array}{l}\text { Type and timing } \\
\text { of screening }\end{array}$ & $\begin{array}{l}\text { 2-hour } 75 \text { g OGTT } \\
\text { at } 24-28 \text { weeks }\end{array}$ & $\begin{array}{l}\text { I-hour } 50 \mathrm{~g} \text { nonfasting GLT at } \\
24-28 \text { weeks } \\
\text { If plasma venous glucose at I hour } \\
\text { is } \geq 10 \mathrm{mmol} / \mathrm{L} \text {, proceed to fasting } \\
3 \text {-hour } 100 \mathrm{~g} \text { OGTT }\end{array}$ & $\begin{array}{l}\text { 2-hour } 75 \mathrm{~g} \text { OGTT } \\
\text { - At 16-18 weeks if previous GDM } \\
\text { - At 24-28 weeks if other risk factors }\end{array}$ & $\begin{array}{l}\text { 2-hour } 75 \text { g OGTT } \\
\text { at } 24-28 \text { weeks }\end{array}$ \\
\hline $\begin{array}{l}\text { Criteria for } \\
\text { diagnosis of GDM }\end{array}$ & $\begin{array}{l}\text { Any one or more of: } \\
\text { Fasting, } \geq 5.1 \mathrm{mmol} / \mathrm{L} \\
\text { I-hour, } \geq 10 \mathrm{mmol} / \mathrm{L} \\
2 \text {-hour, } \geq 8.5 \mathrm{mmol} / \mathrm{L}\end{array}$ & 3-hour $\geq 7.8 \mathrm{mmol} / \mathrm{L}$ & $\begin{array}{l}\text { Any one or more of: } \\
\text { Fasting, } \geq 7.0 \mathrm{mmol} / \mathrm{L} \\
\text { 2-hour, } \geq 7.8 \mathrm{mmol} / \mathrm{L}\end{array}$ & $\begin{array}{l}\text { Any one or more of: } \\
\text { Fasting, } 5.1-6.9 \mathrm{mmol} / \mathrm{L} \\
\text { I-hour, }>10 \mathrm{mmol} / \mathrm{L} \\
\text { 2-hour, } 8.5-11 \mathrm{mmol} / \mathrm{L}\end{array}$ \\
\hline
\end{tabular}

Note: All values given are for plasma venous glucose.

Abbreviations: IADPSG, International Association of Diabetes and Pregnancy Study Groups; NIH, National Institutes of Health; NICE, National Institute for Health Clinical Excellence; ADIPS, Australasian Diabetes in Pregnancy Society; WHO, World Health Organization; BMI, body mass index; GDM, gestational diabetes mellitus; OGTT, oral glucose tolerance test; GLT, glucose loading test. 
growth through increased placental transfer of other growth substrates, such as amino acids and lipids. ${ }^{22}$

The risks to the fetus and newborn arising from maternal GDM are related to both macrosomia and to other proposed pathophysiological effects of fetal hyperglycemia and hyperinsulinism..$^{23-25}$

\section{Intrauterine fetal death and perinatal asphyxia}

Increased fetal substrate uptake arising from chronic fetal hyperinsulinism increases tissue oxygen consumption. This gives rise to relative fetal hypoxia, which increases the risk of intrauterine fetal death, ${ }^{26}$ although the risk of this is less compared to that in maternal type 1 and 2 diabetes mellitus (DM), ${ }^{26}$ and it has been argued that the reported increased risk may be in fact be attributable to undiagnosed type 2 DM. ${ }^{27,28}$ Perinatal asphyxia is also purported to be a potential outcome of relative fetal hypoxia, ${ }^{22,28}$ although macrosomia in itself increases the risk of asphyxia. ${ }^{28,29}$

\section{Premature birth}

The HAPO ${ }^{10}$ study found a continuous linear relationship between the results of glucose tolerance tests and preeclampsia, which is a risk factor for preterm birth. ${ }^{28}$ It has also been shown that, independent of other predisposing factors (including pre-eclampsia, polyhydramnios, and pregnancy induced hypertension), GDM carries an increased risk of spontaneous preterm birth. ${ }^{29}$ Preterm birth is the leading cause of perinatal morbidity and mortality in developed countries. ${ }^{28}$

\section{Polycythemia, hyperviscosity, and hyperbilirubinemia}

Fetal hypoxia drives erythropoiesis, leading to polycythemia, which is defined as a venous hematocrit greater than $65 \%{ }^{30}$ The clinical manifestations of polycythemia and resulting blood hyperviscosity may include plethora, cyanosis, lethargy, jitteriness, hypotonia, feeding difficulties, respiratory distress, hypoglycemia, and hyperbilirubinemia. ${ }^{31}$ Less commonly, necrotising enterocolitis, thrombocytopenia, and venous thrombosis (for example, renal vein thrombosis) may result. ${ }^{31}$ In the HAPO study, there was a weak association between hyperbilirubinemia and maternal blood glucose levels on the OGTT, ${ }^{10}$ but the risk of severe hyperbilirubinemia, such as seen in hemolysis, is low. ${ }^{23}$

\section{Neonatal respiratory distress}

There is evidence from animal models that fetal hyperinsulinism inhibits lung surfactant synthesis. ${ }^{32-34}$
Surfactant deficiency can result in respiratory distress syndrome (also known as hyaline membrane disease), requiring neonatal intensive care (NICU) admission for respiratory support. Other potential causes of respiratory distress in infants born to mothers with GDM include increased risk of premature birth ${ }^{29}$ (also a risk factor for surfactant deficiency) and elective cesarean section delivery due to macrosomia. Elective cesarean section increases the risk of respiratory distress through the mechanism of retained fetal lung fluid. ${ }^{35}$ In a literature review in 2010, Mitanchez ${ }^{26}$ found there was limited data from which to report on the prevalence of respiratory distress in infants born to mothers with GDM, but that as for many other short-term neonatal complications of GDM, there appeared to be an increased risk in macrosomic infants.

\section{Birth injuries}

Shoulder dystocia, and resulting birth injury, is a risk of macrosomia, even in the absence of maternal GDM. ${ }^{36}$ Potential birth injuries include brachial plexus injuries (including Erb's palsy) and fractures of the clavicle and humerus. In a large cohort study in the United States, Zhang et $\mathrm{al}^{37}$ confirmed that the risk of birth injury increases with birth weight: odds ratio $(\mathrm{OR})=2.4$ (95\% confidence interval $[\mathrm{CI}]=2.2-2.5$ ) with a birth weight between 4,500 and 4,999 g, and OR =3.5 (95\% CI =3.0-4.2) with a birth weight $>5,000 \mathrm{~g}$. In a study of perinatal outcomes in women with and without GDM, Esakoff et $\mathrm{al}^{38}$ found that GDM increases the odds of shoulder dystocia (adjusted odds ratios [aORs], 16.4 [GDM] vs 9.6 [non-GDM]) and Erb's palsy (aORs, 41.9 [GDM] vs 6.7 [non-GDM]) associated with a birth weight $\geq 4,000 \mathrm{~g}$.

\section{Hypoglycemia}

The mechanism for hypoglycemia in infants born to mothers with GDM is transient hyperinsulinism, which both inactivates the usual counter-regulatory responses (glycogenolysis, gluconeogenesis, lipolysis, and $\beta$-oxidation of fatty acids) to loss of glucose supply from the placenta, and increases peripheral glucose utilization. ${ }^{39}$ The mainstay of prevention and management of hypoglycemia is prefeed blood glucose monitoring and early and frequent enteral feeding (preferably breast-feeding). Approximately 5\% of infants will have hypoglycemia that cannot be managed with enteral feeding alone and will require intravenous glucose therapy. ${ }^{26}$ Esakoff et $\mathrm{al}^{38}$ found that macrosomia increases the risk of hypoglycemia in infants born to mothers with GDM: neonates with a birth weight of $\geq 4,000 \mathrm{~g}$, compared with those with a birth weight $<4,000 \mathrm{~g}$, had higher frequencies of hypoglycemia 
(5.3\% vs $2.6 \% ; P<0.04)$. Hyperglycemia in labor also increases the risk. ${ }^{40}$

\section{Hypocalcemia}

Functional hypoparathyroidism has been proposed as the basis for hypocalcemia in infants of diabetic mothers. ${ }^{41}$ There is limited data regarding the incidence and significance of neonatal hypocalcemia in GDM. In a retrospective study which was limited by small sample size, Das and Ankola $^{42}$ found an incidence of neonatal hypocalcemia of $6.6 \%$ in GDM compared to $32 \%$ in pregestational diabetes $(P<0.002)$. In a larger study, Cordero et $\mathrm{al}^{43}$ reported the risk to be $<1 \%$.

\section{Hypertrophic cardiomyopathy}

Fetal hyperinsulinism in combination with the normally increased expression and affinity of fetal insulin receptors can lead to proliferation and hypertrophy of cardiac myocytes. ${ }^{44}$ Hypertrophic cardiomyopathy is characterized by thickening of the interventricular septum, and to a lesser degree, the ventricular free walls. It is usually asymptomatic and resolves within the first year of life. ${ }^{44,45}$ The risk of hypertrophic cardiomyopathy is lower in GDM compared to types 1 and $2 \mathrm{DM}^{46}$ but fetal ventricular wall thickening and cardiac function impairment may still be seen, even in the setting of good maternal glycemic control. ${ }^{47}$

\section{Congenital malformations}

The prevalence of major congenital anomalies in the general population has been reported at 23.9 per 1,000 births. ${ }^{48}$ Diabetic embryopathy is well recognized; ${ }^{49}$ the risk of major congenital anomalies in infants born to mothers with type 1 or $2 \mathrm{DM}$ is at least twofold higher ${ }^{50,51}$ compared to the general population, predominantly driven by congenital cardiac disease and nervous system anomalies. ${ }^{51}$ In a recent systematic review, Balsells et $\mathrm{al}^{52}$ found that infants born to women with GDM were at higher risk of congenital malformation compared to the reference population (relative risk [RR] and $95 \% \mathrm{CI}=1.16[1.07-1.25]$ in cohort studies and $\mathrm{OR}=1.4$ [1.22-1.62] in case control studies). However, the risk was much lower than for infants born to mothers with preexisting diabetes, and the contribution of factors such as overt diabetes, age, and maternal BMI, could not be ascertained.

\section{The role of maternal obesity}

The association of obesity with GDM and impact on perinatal outcomes is an important consideration, given that the prevalence of obesity is increasing worldwide, including in women of childbearing age. For example, in the United States, approximately $60 \%$ of women of childbearing are overweight or obese. ${ }^{53}$ Applying the IADPSG diagnostic criteria to make a post hoc diagnosis of GDM, and basing definitions of obesity and overweight at 28 weeks gestation on WHO BMI categories, the HAPO study group showed that both GDM and obesity are independently associated with adverse perinatal outcomes (birth weight, newborn adiposity, and cord C-peptide $>90$ th percentile, primary cesarean section delivery, and pre-eclampsia), and that the combination of obesity and GDM substantially increased the ORs of these outcomes compared to either GDM or obesity alone. ${ }^{54}$

\section{Long-term complications of GDM}

There is a growing awareness that the impact of maternal GDM extends beyond the perinatal period, through childhood and into adulthood. In particular, offspring of mothers with GDM are at risk of obesity, insulin resistance, type 2 DM, and cardiovascular disease. ${ }^{55}$ This is supported by data from epidemiological, animal, and epigenetic studies. ${ }^{45,56,57}$ As the prevalence of both obesity and GDM rises worldwide, the potential public health implications of the flow-on effects on future generations are significant. The concept of an "intergenerational cycle" 19 of diabetes and obesity was first identified in the Pima Indian population, where infants born to mothers with preexisting type 2 DM were more prone to obesity and childhood onset of diabetes compared to infants born to mothers who developed diabetes after pregnancy, ${ }^{19}$ implicating the causal role of the diabetic in utero environment. ${ }^{58}$

\section{Obesity}

In a study of children born to mothers with GDM, Hillier et al ${ }^{59}$ found that an increasing level of hyperglycemia (as measured on OGTT) was associated with a statistically significant greater risk of obesity at 5-7 years of age $(P<0.0001$ for both weight $>85$ th percentile and weight $>95$ th percentile). This effect remained even after adjustment for maternal age, parity, pregnancy weight gain, macrosomia at birth (birth weight $>4,000 \mathrm{~g}$ ), and infant sex. Further supporting the role of maternal hyperglycemia in offspring adiposity, Deierlein et $\mathrm{al}^{60}$ found that in mothers without a diagnosis of preexisting diabetes or of GDM, fetal exposure to elevated maternal glucose concentration was associated with an approximately twofold increase in childhood overweight and obesity, even after adjustment for prepregnancy maternal BMI and infant birth weight $z$ score. 
In comparison, in a systematic review examining the relationship between offspring BMI $z$ score in childhood (age; 3-16 years) and maternal diabetes, Philipps et $\mathrm{al}^{61}$ reported that while the unadjusted mean offspring BMI $z$ score was significantly higher for all types of diabetes (with no evidence of a difference in relation to type of diabetes), this effect was no longer apparent after adjustment for maternal prepregnancy BMI. Likewise, Kim et $\mathrm{al}^{62}$ found that the positive association between maternal GDM and childhood overweight and obesity was consistently attenuated by adjustment for maternal prepregnancy BMI.

The relative contributory roles of the intrauterine environment, shared genes, and postnatal environment on offspring adiposity are as yet unresolved. Maternal obesity remains a significant confounding factor. Given that maternal prepregnancy obesity is more prevalent than GDM, is itself a risk factor for GDM, and is the strongest perinatal predictor of childhood obesity, ${ }^{63}$ Kim et $\mathrm{al}^{62}$ have argued for targeted interventions toward this rather than GDM in isolation.

\section{Insulin resistance, metabolic syndrome, and cardiovascular disease}

In a longitudinal cohort study of children who were large for gestational age (LGA) or appropriate for gestational age (AGA) offspring of mothers with or without GDM, Boney et $\mathrm{al}^{64}$ found that the combination of LGA status and maternal GDM was associated with insulin resistance $(\mathrm{OR}=10.4$, 95\% CI $=1.5-74.4$ ), and a 3.6-fold greater risk of developing metabolic syndrome (obesity, hypertension, dyslipidemia, and glucose intolerance) at 11 years of age. This study was included in a review of nine prospective cohorts of offspring of women with GDM by Burguet ${ }^{55}$ who found evidence of increased glycemic disorders (including type 2 DM). However, as for obesity, the role of in utero exposure could not be distinguished from that of genetic transmission. Tam et $\mathrm{al}^{65}$ have provided some evidence for the influence of the in utero environment: independent of birth weight, and maternal diagnosis of normal glucose tolerance or GDM, in utero hyperinsulinemia (as measured by umbilical C-peptide and insulin levels at birth) was associated with a 17 -fold increase in metabolic syndrome at a mean age of 15 years.

Children with elevated systolic BP are at increased risk of hypertension in adulthood, ${ }^{66}$ which in turn is a risk factor for cardiovascular morbidity and mortality. ${ }^{67,68}$ In a systematic review, Aceti et $\mathrm{al}^{69}$ found that children (age; 2-18 years) of mothers with GDM had a higher systolic blood pressure (BP) compared to controls (mean difference $=1.39 \mathrm{mmHg}, 95 \%$ $\mathrm{CI}=0.00-2.77 ; P=0.05)$. There was no significant difference in diastolic BP. Five out of the 13 included studies reported on prepregnancy BMI. There was a trend toward reduction in mean difference in offspring systolic BP as the difference in maternal BMI between the diabetic and nondiabetic groups reduced, but this was not statistically significant $(P=0.37)$. The systematic review was limited by significant heterogeneity in studies reporting outcomes for GDM, differences in diagnostic criteria for GDM, and lack of reporting of treatment interventions and glycemic control achieved in mothers with GDM.

Novel imaging strategies, which can be performed in the neonatal period, have been suggested as a means of more clearly defining the impact of the intrauterine environment on cardiovascular disease risk. These include carotid and aorta intima-media thickness and retinal vessel imaging. ${ }^{45}$ It remains to be seen how these early measures of cardiovascular health might translate into long-term risk of disease.

\section{Reducing the impact of GDM on offspring: possible solutions}

In view of the short- and long-term health implications of GDM for offspring, and the expected public health burden of increasing rates of type $2 \mathrm{DM}$, metabolic syndrome, and cardiovascular disease, there is an increasing focus on how these impacts can be reduced. Possible solutions fall broadly into four categories: prevention of GDM, optimizing screening for GDM, optimizing treatment of GDM, and postnatal interventions in offspring.

\section{Prevention of GDM}

Prevention of GDM would certainly negate both the maternal and offspring complications of GDM, as well as the debate around optimal diagnostic criteria for and treatment of GDM. Preventative measures include weight management and physical activity. Prepregnancy obesity, as measured by prepregnancy BMI, is a risk factor for the development of $\mathrm{GDM},{ }^{70}$ as is excessive gestational weight gain. ${ }^{71}$ In a review of published literature between 1975 and 2009, Morisset et $\mathrm{al}^{72}$ concluded that while nutritional strategies could be beneficial in reducing the risk of GDM, specific nutritional interventions (such as diet composition) could not be recommended based on available evidence. Higher levels of physical activity both prepregnancy and during early pregnancy appear to protect against development of GDM. ${ }^{73}$

\section{Optimizing screening for GDM}

The IADPSG recommendations represent an attempt to optimize screening for GDM, and signify a move toward 
diagnostic criteria based on increased risk for adverse perinatal outcome. ${ }^{9}$ These recommendations will significantly increase the number of women who are diagnosed with and treated for GDM, but are supported by evidence from two randomized trials ${ }^{74,75}$ which showed benefit from interventions in mild GDM, and by cost-benefit analysis. ${ }^{76}$ However, the recommendations have not been uniformly adopted, and debate remains regarding the costs, risks, and benefits. ${ }^{11,77}$ Hence, the issue of optimal screening criteria for GDM remains unresolved.

\section{Treatment of GDM}

In terms of perinatal complications, the two largest studies to date of effect of treatment of GDM have been the ACHOIS trial ${ }^{75}$ and that of Landon et al. ${ }^{74}$ Both were randomized controlled trials of treatment of mild GDM in populations of women with glucose levels which overlapped with the thresholds for diagnosis recommended by IADPSG, and compared intervention consisting of dietary advice, blood glucose monitoring, and insulin therapy (required by $20 \%$ of women in the ACHOIS trial and $8 \%$ in the Landon et al trial) with usual antenatal care. In the ACHOIS trial, the composite primary outcome (one or more of death, shoulder dystocia, bone fracture, and nerve palsy) was significantly lower in the treatment group ( $1 \%$ vs $4 \%, P=0.01$ ), with a number needed to treat (NNT) of $34(95 \% \mathrm{CI}=20-103) .{ }^{75}$ Landon et $\mathrm{al}^{74}$ found no difference between the intervention and control groups for the composite primary outcome of stillbirth or perinatal death and neonatal complications (including hyperbilirubinemia, hypoglycemia, hyperinsulinemia, and birth trauma), but there were significant reductions in the rates of pre-eclampsia and gestational hypertension, in mean birth weight, neonatal fat mass, frequency of LGA infants, birth weight greater than 4,000 g, shoulder dystocia, and cesarean section delivery.

A number of systematic reviews have summarized the effectiveness of GDM treatment with regards to perinatal outcomes, ${ }^{78-80}$ two of which included the ACHOIS and Landon et al studies. Based on studies which employed a two-step screening approach (glucose challenge test [GCT] and/or screening for risk factors, followed by an OGTT), Horvath et $\mathrm{al}^{80}$ found evidence of a significant reduction in shoulder dystocia and macrosomia with treatment. Falavigna et $\mathrm{al}^{79}$ also found that GDM treatment is effective in reducing shoulder dystocia and macrosomia, and additionally reduces preeclampsia. Horvath et $\mathrm{al}^{80}$ reported that the strongest evidence for benefit from treatment came from studies in which the only pharmacological agent used to manage hyperglycemia was insulin. Falavigna et al ${ }^{79}$ could not distinguish between the benefits of lifestyle interventions vs pharmacological treatments.

There is a paucity of evidence regarding the long-term impacts of treatment of GDM. Neither of the systematic reviews performed by Horvath et al and Falavigna et al could report on long-term benefits of treatment for either women or their offspring. In a study of the children of women who participated in the ACHOIS trial, Gillman et $\mathrm{al}^{81}$ found that even though the prevalence of macrosomia at birth was lower in the intervention group, this did not translate to any significant difference in BMI $z$ score between the intervention and control groups at 4-5 years of age. The authors postulated that the long-term effects of treatment of GDM may not be seen until later in childhood, but did not have access to growth data beyond 5 years of age in the study population. Similarly, Malcolm et al ${ }^{82}$ followed-up offspring of women who had participated in a randomized controlled trial of minimal intervention (control) vs tight glycemic control (intervention) for GDM. Seventy-one children underwent an OGTT between 7 and 11 years of age. There was no significant difference in impaired glucose tolerance between the offspring of the two groups. BMI $<85$ th percentile was found in $75.8 \%$ of offspring of the treatment group and $84.6 \%$ of the offspring of the control group (difference in percentage $=-8.9,95 \%$ $\mathrm{CI}=-27.2$ to 7.8 ). The study was limited by small sample size and potential bias.

\section{Postnatal interventions in offspring}

Feeding mode presents one opportunity for modifying risk in the offspring of women with GDM. In the general population, breast-feeding in comparison to breast milk substitutes is protective against hypertension, insulin resistance and type 2 diabetes, dyslipidemia, and obesity. ${ }^{83,84}$ In particular, Harder et $\mathrm{al}^{85}$ have reported a "dose-response" effect of breast-feeding with respect to obesity, where each additional month of breast-feeding is associated with a $4 \%$ reduction in childhood obesity risk ( $95 \% \mathrm{CI}=-0.06$ to -0.02$)$. The beneficial effects of breast milk feeding appear to be mediated through bioactive nutrients found only in breast milk, a higher protein content, and a slower postnatal growth pattern compared to formula fed infants. ${ }^{83}$ In a retrospective study, Crume et al ${ }^{84}$ examined the impact of breast-feeding on childhood adiposity following in utero exposure to diabetes (prepregnancy diabetes or GDM). They reported that breast-feeding for 6 months or longer (compared to less than 6 months) was associated with significantly lower BMI, waist 
circumference, and visceral and subcutaneous adipose tissue at 6-13 years of age.

\section{Conclusion}

In summary, the prevalence of GDM is rising worldwide. The significant short-and long-term consequences of GDM for offspring necessitate action. Current efforts are focused on the development and adoption of diagnostic screening criteria that appropriately identify women and their offspring who are most likely to benefit from treatment. Randomized controlled trials demonstrate that treatment of GDM reduces macrosomia, which is a significant risk factor for perinatal complications. With regards to solutions to the long-term complications, which carry the greatest public health significance, further understanding of the relative contributory roles of the intrauterine environment, shared genes, and postnatal environment is required. Maternal obesity in particular remains a significant confounding factor; prepregnancy weight loss interventions carry the potential to ameliorate the effects of both maternal obesity and GDM on future generations. In terms of postnatal interventions, breastfeeding appears to have a protective effect. Randomized controlled trials that are long-term and involve large cohorts are required to determine which other pre-, peri-, and postnatal interventions will be most effective in reducing the long-term risk of Type 2 DM, obesity and cardiovascular disease in offspring of women with GDM.

\section{Disclosure}

The authors report no conflicts of interest in this work.

\section{References}

1. Metzger B, Coustan D. Summary and recommendations of the Fourth International Workshop-Conference on Gestational Diabetes Mellitus: the organising committee. Diabetes Care. 1998;21(Suppl 2): B161-B167.

2. Ferrara A, Kahn H, Quesenberry C, Riley C, Hedderson M. An increase in the incidence of gestational diabetes mellitus: Northern California, 1991-2000. Obstet Gynecol. 2004;1033:526-533.

3. Anna V, van der Ploeg H, Cheung N, Huxley R, Bauman A. Sociodemographic correlates of the increasing trend in prevalence of gestational diabetes mellitus in a large population of women between 1995 and 2005. Diabetes Care. 2008;31:2288-2293.

4. Cheung N, Byth K. Population health significance of gestational diabetes. Diabetes Care. 2003;267:2005-2009.

5. Ferrara A, Hedderson M, Quesenberry C, Selby J. Prevalence of gestational diabetes mellitus detected by the National Diabetes Data Group or the Carpenter and Coustan plasma glucose thresholds. Diabetes Care. 2002;259:1625-1630.

6. Buckley B, Harreiter J, Damm P, et al. Gestational diabetes mellitus in Europe: prevalence, current screening practice and barriers to screening. A review. Diabet Med. 2012;29(7):844-854.

7. Carolan M, Davey M, Biro M, Kealy M. Maternal age, ethnicity and gestational diabetes mellitus. Midwifery. 2012;28:778-783.
8. Australian Institute of Health and Welfare 2010. Diabetes in pregnancy: its impact on Australian women and their babies. [Diabetes series no 14. Cat no CVD 52]. Canberra, Australia: AIHW. Available from: http://www.aihw.gov.au/publication-detail/?id=6442472448. Accessed January 7, 2015.

9. International Association of Diabetes and Pregnancy Study Groups Consensus Panel. International association of diabetes and pregnancy study groups recommendations on the diagnosis and classification of hyperglycemia in pregnancy. Diabetes Care. 2010;33(3):676-682.

10. The HAPO Study Cooperative Research Group. Hyperglycemia and adverse pregnancy outcomes. $N$ Engl J Med. 2008;358(19): 1991-2002.

11. Cundy T, Ackermann E, Ryan E. Gestational diabetes: new criteria may triple the prevalence but effect on outcomes in unclear. $B M J$. 2014;348:g1567.

12. Royal College of Obstetricians and Gynaecologists. Scientific Impact Paper No 23. Diagnosis and Treatment of Gestational Diabetes. 2011. Available from: http://www.rcog.org.uk/globalassets/documents/ guidelines/sip_no_23.pdf. Accessed January 7, 2015.

13. National Institute for Health and Clinical Excellence. NICE clinical guideline 63: diabetes in pregnancy. Management of diabetes and its complications from pre-conception to the postnatal period. London, UK: NICE; 2008

14. American Diabetes Association. Standards of medical care in diabetes 2014. Diabetes Care. 2014;37(Suppl 1):S14-S80.

15. adips.org [homepage on the Internet]. Sydney: Australasian Diabetes in Pregnancy Society [updated Jun 2014; cited September 29]. Available from: http://adip.org/. Accessed January 7, 2015.

16. Report of a World Health Organization consultation diagnostic criteria and classification of hyperglycaemia first detected in pregnancy: a World Health Organization guideline. Diabetes Res Clin Pract. 2014;103: 341-363.

17. ranzcog.edu.au [homepage on the Internet]. Melbourne: Royal Australian and New Zealand College of Obstetricians and Gynaecologists [cited September 29, 2014]. Available from: https://www.ranzcog.edu.au/ womens-health/college-communiques/1392-diagnosis-of-gestationaldiabetes-mellitus-gdm-in-australia.html. Accessed January 7, 2015.

18. Catalano P, Tyzbir E, Roman N, Amini S, Sims E. Longitudinal changes in insulin release and insulin resistance in non-obese pregnant women. Am J Obstet Gynecol. 1991;165:1667-1672.

19. Battista M, Hivert M, Duval K, Baillargeon J. Intergenerational cycle of obesity and diabetes: how can we reduce the burdens of these conditions on the health of future generations? Exp Diabetes Res. 2011;2011:596060.

20. Pedersen J. Diabetes and Pregnancy: Blood Sugar of Newborn Infants [doctoral thesis]. Copenhagen, Denmark: Danish Science Press; 1952.

21. Henriksen T. The macrosomic fetus: a challenge in current obstetrics. Acta Obstet Gynecol Scand. 2008;87:134-145.

22. Schwartz R, Gruppuso P, Petzold K, Brambilla D, Hiilesmaa V, Teramo K. Hyperinsulinemia and macrosomia in the fetus of the diabetic mother. Diabetes Care. 1994;18:640-648.

23. Mitanchez D, Yzydorczyk C, Siddeek B, Boubred F, Benahmed M, Simeoni U. The offspring of the diabetic mother - short- and long-term implications. Best Pract Res Clin Obstet Gynaecol. Epub August 20, 2014.

24. Dudley D. Diabetic-associated stillbirth: incidence, pathophysiology, prevention. Obstet Gynecol Clin North Am. 2007;34:293-307.

25. Mathiesen E, Ringholm L, Damm P. Stillbirth in diabetic pregnancies. Best Pract Res Clin Obstet Gynaecol. 2011;25:105-111.

26. Mitanchez D. Foetal and neonatal complications in gestational diabetes: perinatal mortality, congenital malformations, macrosomia, shoulder dystocia, birth injuries, neonatal complications. Diabetes Metab. 2010;36:617-627.

27. Persson B, Hanson U. Neonatal morbidities in gestational diabetes mellitus. Diabetes Care. 1998;21(Suppl 2):B79-B84.

28. Goldenberg R, Culhane J, Iams J, Romero R. Epidemiology and causes of preterm birth. Lancet. 2008;371(9606):75-84. 
29. Hedderson M, Ferrara A, Sacks D. Gestational diabetes mellitus and lesser degrees of pregnancy hyperglycemia: association with increased risk of spontaneous preterm birth. Obstet Gynecol. 2003;102: $850-856$.

30. Linderkamp O. Blood Viscosity of the Neonate. Neoreviews. 2004; 5(10):e406-e416.

31. Wiswell T, Cornish J, Northam R. Neonatal polycythemia: frequency of clinical manifestations and other associated findings. Pediatrics. 1986;78(1):26-30

32. Carrapato M. The offspring of gestational diabetes. J Perinat Med. 2003;31:5-11.

33. Levine D. Hyperinsulinaemia and decreased surfactant in fetal rabbits. Dev Pharmacol Ther. 1985;8:284-291.

34. Warburton D. Chronic hyperglycaemia with secondary hyperinsulinaemia inhibits the maturational response of fetal lamb lungs to cortisol. J Clin Invest. 1983;72:433-440.

35. Signore C, Klebanoff M. Neonatal morbidity and mortality after elective cesarean delivery. Clin Perinatol. 2008;35(2):361-371.

36. Linder N, LahatY, Kogan A, et al. Macrosomic newborns of non-diabetic mothers: anthropometric measurements and neonatal complications. Arch Dis Child Fetal Neonatal Ed. 2014;99:F353-F358.

37. Zhang X, Decker A, Platt R, Kramer M. How big is too big? the perinatal consequences of macrosomia. Am J Obstet Gynecol. 2008;198(5): e511-e516.

38. Esakoff TF, Cheng YW, Sparks TN, Caughey AB. The association between birthweight $4000 \mathrm{~g}$ or greater and perinatal outcomes in patients with and without gestational diabetes. Am J Obstet Gynecol. 2009;200:672. e1-672. e4.

39. Williams A. Hypoglycaemia of the newborn: a review. Bull World Health Organ. 1997;75(3):261-290.

40. Balsells M, Corcoy R, Adelantado J, Garcia-Patterson A, Altirriba O, de Leiva A. Gestational diabetes mellitus: metabolic control during labour. Diabetes Nutr Metab. 2000;13:257-262.

41. Tsang R, Chen I, Friedman M, Gigger M, Steichen J, Koffler H. Parathyroid function in infants of diabetic mothers. J Pediatr. 1975; 86(3):399-404.

42. Das S, Ankola P. Infants born to mothers with pre-gestational diabetes have a higher risk of developing neonatal hypocalcemia compared to mothers with gestational diabetes. J Neonatol Res. 2012;2(3): 130-133.

43. Cordero L, Treuer S, Landon M, Gabbe S. Management of infants of diabetic mothers. Arch Pediatr Adolesc Med. 1998;152:249-254.

44. Hornberger L. Maternal diabetes and the fetal heart. Heart. 2006;92(8): 1019-1021

45. Marco L, McCloskey K, Vuillermin P, Burgner D, Said J, Ponsonby A. Cardiovascular disease risk in the offspring of diabetic women: the impact of the intrauterine environment. Exp Diabetes Res. 2012;2012:565160.

46. Ullmo S, Vial Y, Di Bernardo S, et al. Pathological ventricular hypertrophy in the offspring of diabetic mothers: a retrospective study. Eur Heart J. 2007;28:1319-1325.

47. Chu C, Gui Y, Ren Y. The impacts of maternal gestational diabetes mellitus on fetal hearts. Biomed Environ Sci. 2012;25(1): $15-22$.

48. Dolk H, Loane M, Garne E. The prevalence of congenital anomalies in Europe. Adv Exp Med Biol. 2010;686:349-364.

49. Loeken M. Challenges in understanding diabetic embryopathy. Diabetes. 2008;57:3187-3188.

50. Correa A, Gilboa S, Besser L, et al. Diabetes mellitus and birth defects. Am J Obstet Gynecol. 2008;199(3):237. e1-e9.

51. Macintosh M, Fleming K, Bailey J, Miller A. Perinatal mortality and congenital anomalies in babies of women with type 1 or type 2 diabetes in England, Wales and Northern Ireland: population based study. BMJ. 2006;333:177.

52. Balsells M, Garcia-Patterson A, Gich I. Major congenital malformations in women with gestational diabetes mellitus: a systematic review and meta-analysis. Diabetes Metab Res Rev. 2012;28:252-257.
53. Flegal K, Carroll M, Ogden C, Curtin L. Prevalence and trends in obesity among US adults, 1999-2008. JAMA. 2010;303:235-241.

54. HAPO Study Cooperative Research Group. The hyperglycaemia and adverse pregnancy outcome study: associations of GDM and obesity with pregnancy outcomes. Diabetes Care. 2012;35:780-786.

55. Burguet A. Long-term outcome in children of mothers with gestational diabetes. Diabetes Met. 2010;36:682-694.

56. Mitanchez D. Infants born to mothers with gestational diabetes mellitus: mild neonatal effects, a long-term threat to global health. $J$ Pediatr. 2014;164(3):445-450.

57. Lehnen H, Zechner U, Haaf T. Epigenetics of gestational diabetes mellitus and offspring health: the time for action is in early stages of life. Mol Hum Reprod. 2013;19(7):415-422.

58. Dabelea D, Pettitt D. Intrauterine diabetic environment confers risks for type 2 diabetes mellitus and obesity in the offspring, in addition to genetic susceptibility. J Pediatr Endocrinol Metab. 2001;14(8):1085-1091.

59. Hillier T, Pedula K, Schmidt M, Mullen J. Childhood obesity and metabolic imprinting: the ongoing effects of maternal hyperglycemia. Diabetes Care. 2007;30(9):2287-2292.

60. Deierlein A, Siega-Riz A, Chantala K, Herring A. The association between matneral glucose concentration and child BMI at age 3 years. Diabetes Care. 2011;34:480-484.

61. Philipps L, Santhakumaran S, Gale C, et al. The diabetic pregnancy and offspring BMI in childhood: a systematic review and meta-analysis. Diabetologica. 2011;54:1957-1966.

62. Kim S, Sharma A, Callaghan W. Gestational diabetes and childhood obesity: what is the link? Curr Opin Obstet Gynecol. 2012;24(6): 376-381.

63. Catalano P, Farrell K, Thomas A, Huston-Presley L. Perinatal risk factors for childhood obesity and metabolic dysregulation. Am J Clin Nutr. 2009;90:1303-1313.

64. Boney C, Verma A, Tucker R, Vohr B. Metabolic syndrome in childhood: association with birth weight, maternal obesity, and gestational diabetes mellitus. Pediatrics. 2005;115:e290-e296.

65. Tam W, Wan Ma R, Yang X, et al. Glucose intolerance and cardiometabolic risk in adolescents exposed to maternal gestational diabetes. Diabetes Care. 2010;33:1382-1384.

66. Sun S, Grave G, Siervogel R, Pickoff A, Arslanian S, Daniels S. Systolic blood pressure in childhood predicts hypertension and metabolic syndrome later in life. Pediatrics. 2007;119:237-246.

67. Kannel W, Vasan R, Levy D. Is the relation of systolic blood pressure to risk of cardiovascular disease continuous and graded, or are there critical values? Hypertension. 2003;42:453-456.

68. National Insttute for Health and Care Excellence. NICE guideline 127. Hypertension: clinical management of primary hypertension in adults. 2011.

69. Aceti A, Santhakumaran S, Logan K, et al. The diabetic pregnancy and offspring blood pressure in childhood: a systematic review and meta-analysis. Diabetologica. 2012;55:3114-3127.

70. Torloni M, Betrán A, Horta B, et al. Prepregnancy BMI and the risk of gestational diabetes: a systematic review of the literature with metaanalysis. Obes Rev. 2009;10(2):194-203.

71. Cheng Y, Chung J, Kurbish-Block I, Inturrisi M, Shafer S, Caughey A. Gestational weight gain and gestational diabetes mellitus: perinatal outcomes. Obstet Gynecol. 2008;112:1015-1022.

72. Morisset A, St-Yves A, Veillette J, Weisnagel S, Tchernof A, Robitaille J. Prevention of gestational diabetes mellitus: a review of studies on weight management. Diabetes Metab Res Rev. 2010;26(1):17-25.

73. Tobias D, Zhang C, van Dam R, Bowers K, Hu F. Physical activity before and during pregnancy and risk of gestational diabetes mellitus. Diabetes Care. 2011;34(1):223-229.

74. Landon M, Spong C, Thom E, et al. A multicenter, randomised trial of treatment for mild gestational diabetes. $N$ Engl J Med. 2009;361: 1339-1348.

75. Crowther C, Hillier J, Moss J, McPhee A, Jeffries W, Robinson J. Effect of treatment of gestational diabetes mellitus on pregnancy outcomes. N Engl J Med. 2005;352(24):2477-2486. 
76. Mission J, Ohno M, Cheng Y, Caughey A. Gestational diabetes screening with the new IADPSG guidelines: a cost-effectiveness analysis. Am J Obstet Gynecol. 2012;207(4):326:e321-e329.

77. Werner E, Pettker C, Zuckerwise L, Reel M, Funai E, Henderson J. Screening for gestational diabetes mellitus: are the criteria proposed by the international association of the Diabetes and Pregnancy Study Groups cost-effective? Diabetes Care. 2012;2012(35):529-535.

78. Alwan N, Tuffnell D, West J. Treatments for gestational diabetes. Cochrane Database Syst Rev. 2009;3:CD003395.

79. Falavigna M, Schmidt M, Trujillo J, et al. Effectiveness of gestational diabetes treatment: a systematic review with quality of evidence assessment. Diabetes Res Clin Pract. 2012;98:396-405.

80. Horvath K, Koch K, Jeitler K, et al. Effects of treatment in women with gestational diabetes mellitus: systematic review and meta-analysis. $B M J$. 2010;340:c1395
81. Gillman M, Oakey H, Baghurst P, Volkmer R, Robinson J, Crowther C. Effect of treatment of gestational diabetes mellitus on obesity in the next generation. Diabetes Care. 2010;33(5):964-968.

82. Malcolm J, Lawson M, Gaboury I, Lough G, Keely E. Glucose tolerance of offspring of mother with gestational diabetes mellitus in a low-risk population. Diabet Med. 2006;23(5):565-570.

83. Lanigan J, Singhal A. Early nutrition and long-term health: a practical approach. Proc Nutr Soc. 2009;68:422-429.

84. Crume T, Ogden L, Maligie M, et al. Long-term impact of neonatal breastfeeding on childhood adiposity and fat distribution among children exposed to diabetes in utero. Diabetes Care. 2011;34(3):641-645.

85. Harder T, Bergmann R, Kallischnigg G, Plagemann A. Duration of breastfeeding and risk of overweight: a meta-analysis. Am J Epidemiol. 2005;162:397-403.

\section{Publish your work in this journal}

Research and Reports in Neonatology is an international, peer-reviewed, open access journal publishing original research, reports, editorials, reviews and commentaries on neonatal health. The manuscript management system is completely online and includes a very quick and fair peer-review system. Visit http://www.dovepress.com/testimonials.php to read real quotes from published authors. 